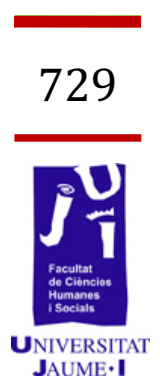

\title{
An Analysis of Blogs in Communicative Classrooms: Exploring its Potential
}


The use of Information and Communication Technologies (ICTs) in language learning and teaching has greatly increased in the last decade. Among the different technological tools used in the learning process, blogs have gained popularity among educators and students (Trajtemberg \& Yiakoumetti, 2011; Lai \& Chen, 2010). This article focuses on how blogs can be incorporated into a communicative classroom through a Task-based Language Teaching approach (TBLT) (Ellis \& Shintani, 2014; Willis 1996). This paper offers a theoretical study about the potential of blogs in TBLT instruction. Firstly, it explores the use of blogs in an English as a foreign language (EFL) classroom, explaining its benefits. Secondly, it focuses on the advantages of using a communicate approach in the EFL classroom, paying special attention to the elaboration and implementation of tasks. This paper will conclude with a section of pedagogical implications in which a teaching proposal will be presented taking into account the educational context of the participants in order to show the different implications of blogs in a foreign language classroom.

Keywords: blog, TBLT, CLT, task, communicative competence.

\section{Introduction}

Blogs can be defined as websites in which users, also called "bloggers", can post items which appear in reverse chronological order. Items posted in blogs are also known as "posts" or "entries". The term blog comes from the shortening of the word weblog. Nowadays, there exist many different platforms that let bloggers to create and customize blogs in few minutes for free.

In the last decade, the use of blogs in educational contexts has increased. Many teachers and researchers have proved the benefits of using this tool to assist teaching (Lai \& Chen, 2010). They have realized that blogs are the perfect tool to monitor the language learning and teaching outside the classroom.

At the same time, communicative language teaching (CLT) approaches has gained ground as one of the most important methodologies for teaching and learning English. Due to the importance of CLT, two strong versions of this approach have emerged: Content and Language Integrated Learning (CLIL) and Task-based language teaching (TBLT). For exploring the potential of blogs in communicative classrooms, TBLT is the approach to be considered in which students will have to fulfill different tasks in order to reach a final outcome. 


\section{Objectives}

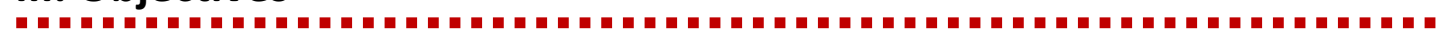

Although there is great interest in the affordances that blogs have in educational settings and their future use in education, there has been relatively little said about the potential of blogs in TBLT instruction.

In this paper, I will explore the use of blogs in education, explaining its main advantages. Secondly, I will focus on the advantages of using a communicative approach in the EFL classroom paying special attention to TBLT methodology. Then, I will explain the origins of this approach and I will focus on the definition and types of tasks. The last section of this paper will include a pedagogical proposal where different tasks and activities to be applied in the FL classroom through a blog will be described.

\section{Method}

This research project was developed in the year 2014 as part of a university subject. After conducting some research on language for tourism, it was observed that it was essential to investigate its main features. After observing the main characteristics of this language, the next step was to study them through a blog in a communicative classroom to analyze its potential. However, as it was really difficult to conduct a qualitative study due to time and resource limitations, a theoretical study was selected including a possible pedagogical proposal.

To start writing this paper, a lot of research on published material was done to be able to analyze the features of the language for tourism as well as the potential of blogs in communicative classrooms. With the information obtained, a pedagogical proposal focusing on the language for tourism was designed to be applied in a FL classroom. Finally, the pros and cons of the pedagogical proposal were analyzed.

\section{Blogs}

Blogs are a really powerful tool for language teaching and learning. Both students and teachers can benefit from the affordances provided by this tool in order to improve the language learning process. This section presents the main advantages when using blogs in EFL contexts and they are as follows: 1) Sense of community, 2) Constructivism and collaboration, 3) Learner's motivation and 4) Interaction.

\subsection{Sense of community}

Blogs create a sense of community around people with the same interests. This space offers different people with the same concerns feel part of a big family. In the literature, different definitions of sense of community can be found (e.g. McMillan \& Chavis, 1986 or Sarason, 1974). According to McMillan and Chavis (1986), sense of community can be defined as "a feeling that members matter to one another and to the group, and a shared faith that members' needs will be meet through their 
commitment to be together" (p.9). Nowadays, two essential concepts related to sense of community can be highlighted: interdependence and supportive interpersonal relationships (Halic et al, 2010). By interdependence, it is understood that the individual is accepted, valued and respected by the group and at the same time, the individual identifies with the group. On the other hand, the need of belonging to any group is accomplished by supportive interpersonal relationships. Therefore, blogs are going to create bonds among individuals with similar interests and they are going to build a sense of belonging to a community in which participants are connected and respected. This atmosphere will enhance the process of language learning.

\subsection{Constructivism and collaboration}

Blogs are great tools for collaborative projects where every single participant can make his or her own contributions making students feel involved in the different tasks. What is more, blogs offer opportunities for students to engage with their classmates' work promoting collaboration among them.

Through blogs, students are engaged in meaningful discourse to construct their own meaning and to share this meaning with other students in order to validate their understanding (Garrison \& Akyol, 2009). However, this collaboration is difficult in classes with a big number of students.

According to Trajtemberg \& Yiakoumetti, "weblogs (or blogs), have the potential of being a unique learning venue where collaboration can take place and interaction among L2 participants can be promoted"(2014:1). These two authors also believe that blogs promote scaffolding and students with less knowledge can learn from advanced students just working together by means of peers' work.

\subsection{Learners' motivation}

One of the main advantages of blogs deals with the motivation of the students. According to Trajtemberg \& Yiakoumetti, "blogs can lead to enhanced motivation for interaction and self-expression"(2014:3). Students are bored of textbooks and traditional methodologies. In the 21th Century, new technologies have gained ground and they are changing the educational field. It is paramount to mention that blogs enhance students' motivation due to the fact that they are working with ICTs in a friendly atmosphere where everybody can learn and teach. What is more, students' enjoyment increases teachers' disposition to spend more time teaching through blogs (Lai \& chen, 2011).

\subsection{Blogs foster interaction}

Blogs create a space where social interaction is possible, thus creating a favorable environment for language learning. According to Trajtemberg \& Yiakoumetti, "the potential for interaction inherent in blogs resides in the content of the posts, the blogger's self-reflection, and other bloggers' reactions" (2014:2). Blogs are channels for exchanging opinions through 
the interaction of the different participants in the blog. This interaction among participants enhances learning.

In the EFL classroom, blogs become channels where students can interact in order to achieve real communication. These platforms are considered authentic interactive contexts where communication and interaction are promoted. (Trajtemberg \& Yiakoumetti, 2014).

\section{Communicative approaches within the EFL classroom}

In this section, the advantages of using communicative approaches within the EFL classroom are going to be considered. After analyzing the different advantages, special attention will be paid to TBLT and how to implement this approach in the classroom.

First of all, communicative approaches promote real communication among students within the classroom. This real communication is going to be achieved through realistic and meaningful Interaction. What is more, Communicative Language Teaching (CLT) not only focuses on fluency but also on accuracy. Teachers can use different strategies to emphasize different aspects of the language in different moments. Another advantage of using a communicative approach in the classroom deals with the fact that CLT motivates students. By using this methodology, students are going to feel a real need for using the language and thus motivation is going to increase. Finally, it is also essential to mention that the final goal of CLT is to promote learning.

\section{TBLT}

CLT emerged with the aim of developing learners' communicative competence. Due to the importance of this approach, CLT has evolved and two strong versions of this method exist: Task-based language teaching (TBLT) and Content and Language Integrated Learning (CLIL).

For this study, TBLT methodology is the one that is going to be taken into account. TBLT is considered a contemporary view of language learning. According to Ellis \& Shintani, the aim of this approach is "to develop learners' communicative competence by engaging them in meaningfocused communication through the performance of tasks" (2014:135). Through this approach, learners are engaged in real language use in the classroom through the fulfillment of tasks.

In TBLT, lessons are seen as social events where students are active learners. They are the ones who are going to fulfil tasks in order to arrive to a final outcome. The role of students change to communicators and the role of the teacher is that of facilitator (Ellis \& Shintani 2014). Teachers are not anymore the ones who direct the class; they just monitor and guide the learning process.

In this approach tasks are the core unit of planning and instruction in language teaching. Therefore, it is essential to define them. In the literature, many different definitions of tasks can be found (e.g. Prabhu, 1987, Willis 1996, etc). According to Prabhu "a task is an activity which 
required learners to arrive at an outcome from given information through some process of thought, and which allowed teachers to control and regulate that process" (1987:24). Prabhu's definition is really complete, as this author focuses on both, the role of learners and teachers.

Ellis, in the year 2003, established four features that any task should have. For establishing these criteria, she took into account the different definitions that had appeared until that moment.

1. Tasks should focus on meaning

2. There should be a gap

3. Learners should use their own resources

4. There should be a clearly defined communicative outcome

Apart from these four features established by Ellis, it is also essential to look for authenticity when designing or working with tasks. Tasks must reflect real-life use of the language. What is more, teachers and educators must use realia and authentic materials in their lessons to achieve this authenticity.

There are also many different classifications of tasks (e.g. Willis (1996), Prabhu (1987) or Ellis \& Shintani (2014)). Among these classifications, tasks can be divided in focused or unfocused; information gap, opinion gap or reasoning gap and input-based or output-based tasks. Other examples of tasks are: jigsaw, problem solving, decision making, opinion exchange or collaborative tasks. This last type includes the famous dictogloss and text reconstruction tasks.

Another important step when dealing with TBLT is its implementation in the classroom. Among the different models proposed (e.g. Lee (2000), Prabhu (1987), Skehan (1996), Willis (1996), etc); they all have in common the three principal phases: a pre-task, a main-task and a post-task phase.

In the pre-task, students are going to get some background information about the topic they are going to deal with. In the while-task, students will have to work on different aspects or features that will be necessary to accomplish the final tasks. And finally, in the post-task, students will get some reinforcement about the tasks they have just accomplished.

\section{Pedagogical proposal}

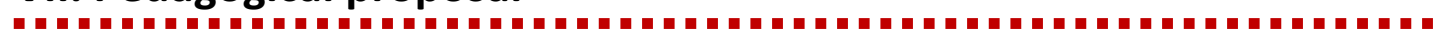

This section proposes a pedagogical proposal to be implemented in an EFL classroom. After explaining the proposal, special attention will be paid to the pros and cons of this specific task.

It is essential to mention that this teaching proposal can be adapted in order to fit other educational levels. However, this proposal has been devised bearing in mind a group of 25 students belonging to the 2 nd year of Bachillerato in a Spanish high school.

Students in 2nd year of Bachillerato are between 17 and 18 years old. They are quite motivated because this is the last year they have to accomplish to be able to go to the university. What is more, getting good marks is also essential for them. Depending on their marks they will be able 
to access to one Bachelor's degree or another. So, all these factors are going to favour their attitude towards the English language.

Students are supposed to have a B1 level according to the CEFR. With this intermediate level, students are supposed to be independent users of the English language. The CEFR establishes in its official website1 that B1 students:

- "can understand the main points of clear standard input on familiar matters regularly encountered in work, school, leisure, etc.

- Can deal with most situations likely to arise whilst travelling in an area where the language is spoken.

- Can produce simple connected text on topics which are familiar or of personal interest.

- Can describe experiences and events, dreams, hopes and ambitions and briefly give reasons and explanations for opinions and plans."

The first step teachers must do in order to design this proposal is to create a blog in one of the many blog platforms available in the Internet. For this pedagogical proposal, the google's free tool for creating blogs, Blogger ${ }^{2}$, has been chosen. The official website of this platform offers many different templates for free in order to customize the design of the blog.

The name of the blog created for this proposal is "Learning English can be fun" (see figure 1). In the blog, students can find a character called Lucy. Lucy is a virtual avatar, i.e a voki (see figure 2) whose role is to assist the teacher in the teaching process. Lucy is going to be students' Irish virtual friend and through her, teachers will introduce all the contents and activities of the blog.

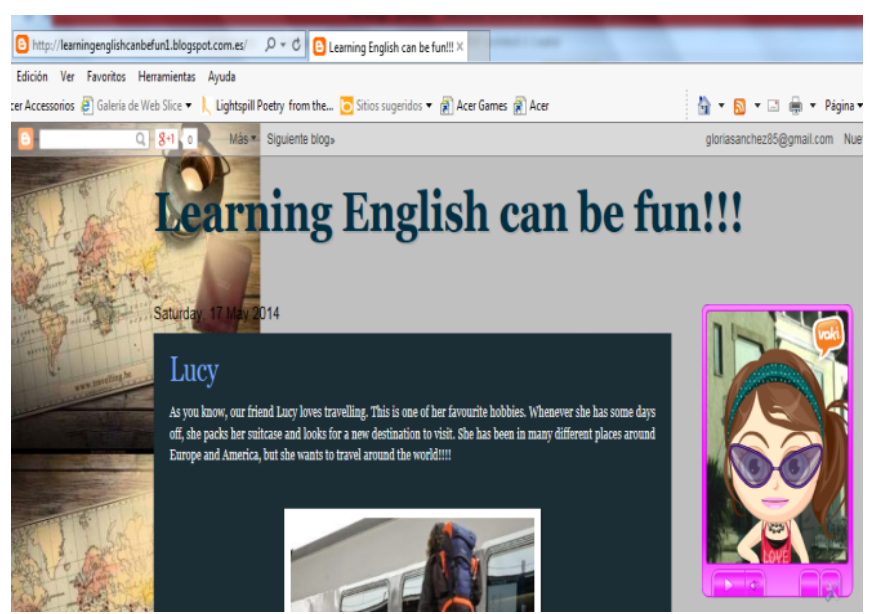

Figure 1. Blog "Learning English can be fun"

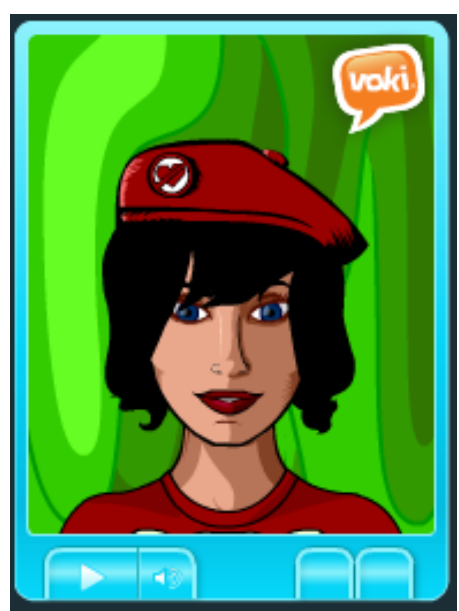

Figure 2. Lucy

\footnotetext{
${ }^{1}$ https://www.eui.eu/Documents/ServicesAdmin/LanguageCentre/CEF.pdf 2 https://www.blogger.com/home

3 http://learningenglishcanbefun1.blogspot.com.es/
} 
The final aim or task of this specific teaching proposal is for students to be able to write a travel review using online resources and all they are going to learn about evaluative adjectives. For doing that, this proposal in divided into three different parts following a TBLT methodology: a pre-task, a while-task and a post-task.

\section{PRE-TASK:}

The pre-task is essential in order to make students aware of the topic they are going to deal with. What is more, in this step learners are going to acquire the necessary vocabulary and skills needed to accomplish the final task.

In the pre-task, students are going to find background information about tourism and reviews. Furthermore, they will have the opportunity to analyze travel diaries and travel reviews (see figure 3 ), and to explore Tripadvisor (see picture 4) which is the world's largest travel site.

Trust me I am not that easily disgusted but this was simply the most horrible experience I have ever had! First of all, the staff were totally unhelpful and unfriendly during our stay!

This place was not only dirty but filthy and beyond disgusting! I had to check out the next day as I felt I put my health at risk by staying there.

The floor itself was so nasty that I had to wonder if this room had been cleaned at all in between guests, since there was a lot of rubbish still left behind from previous guests. The bathroom was in an overly creepy state as well, which is why I didn't even dare to take a shower. It was just a never ending story of finding hairs and stains on the sheets etc.

Figure 3. Example of travel review taken from TripAdvisor

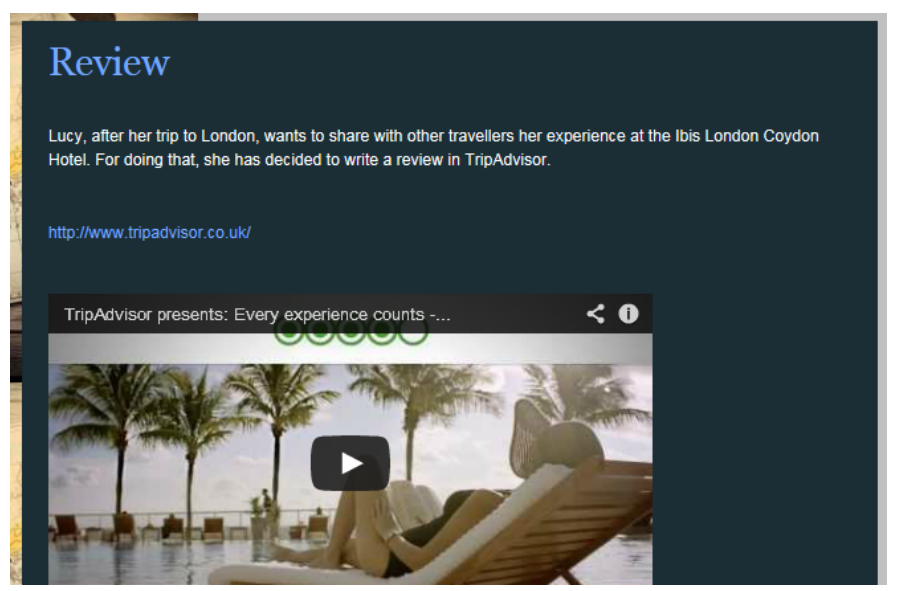

Figure 4. TripAdvisor promotional video

\section{WHILE-TASK:}

In this stage, students will have to work on the different aspects of a review focusing on its structure, the different types of reviews that exist and the evaluative vocabulary used in reviews in order to denote positive and negative values (see figure 5). 

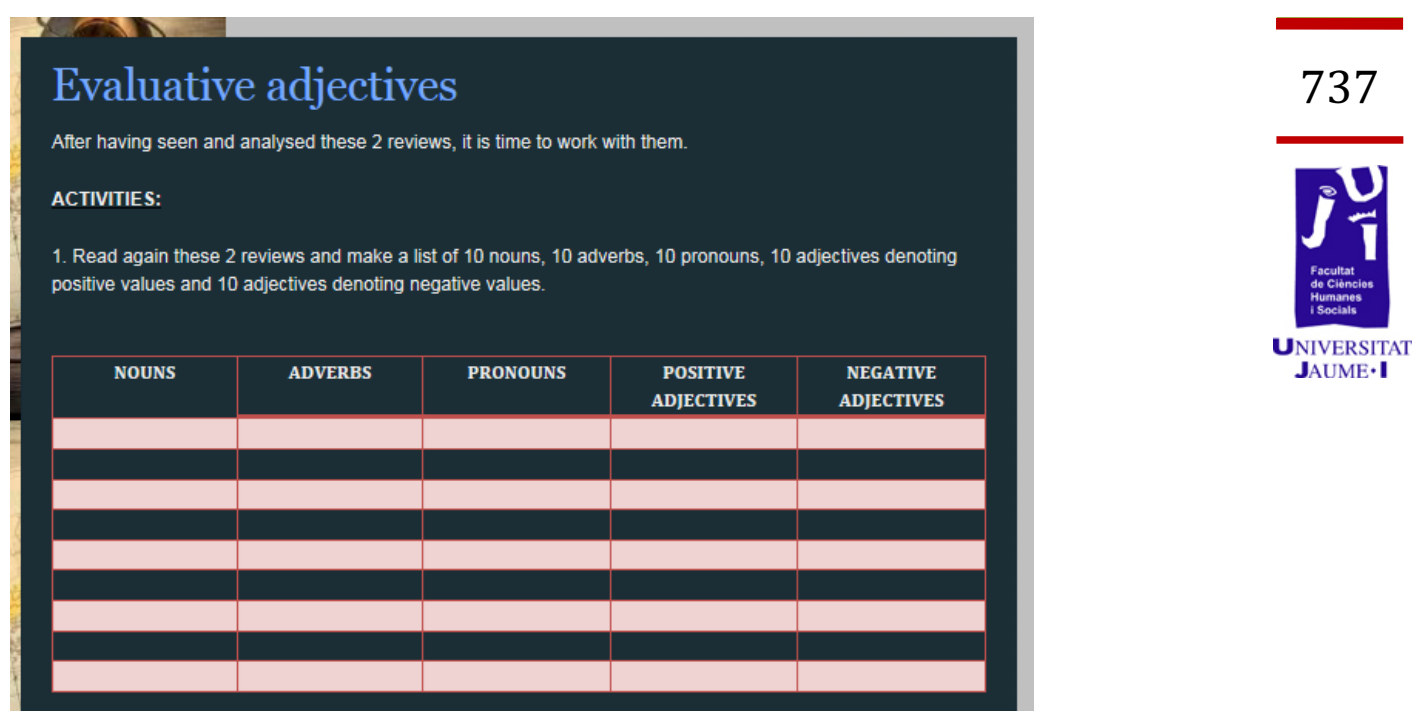

Figure 5. Activity to work on evaluative adjectives

Many of the activities proposed to reinforce students' knowledge will be created using the platform "Hot potatoes" (see figure 6). These activities will help learners to accomplish the final task. Students will deal with matching, crossing and ordering activities.

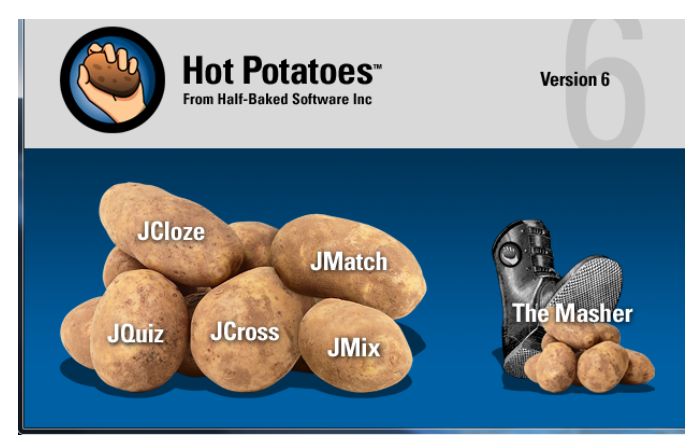

Figure 6. Hot Potatoes software

It is also important to mention that in order to master the use of evaluative adjectives, students are going to work with two pairs of similar adjectives that at first sight seem synonyms. They are going to analyze its differences and peculiarities. They are going to contrast the pair of adjectives pleasant vs. nice and horrible vs. terrible.

In order to master the use of these adjectives, inductive activities have been designed in which students will have to guess from the context which is the rule of use of each one of these adjectives (see figure 7). After completing these activities, students will have to analyze the use of these words in a corpus where they will be able to obtain real examples. It is essential to mention that all these activities have been designed using real corpus to offer authenticity. 

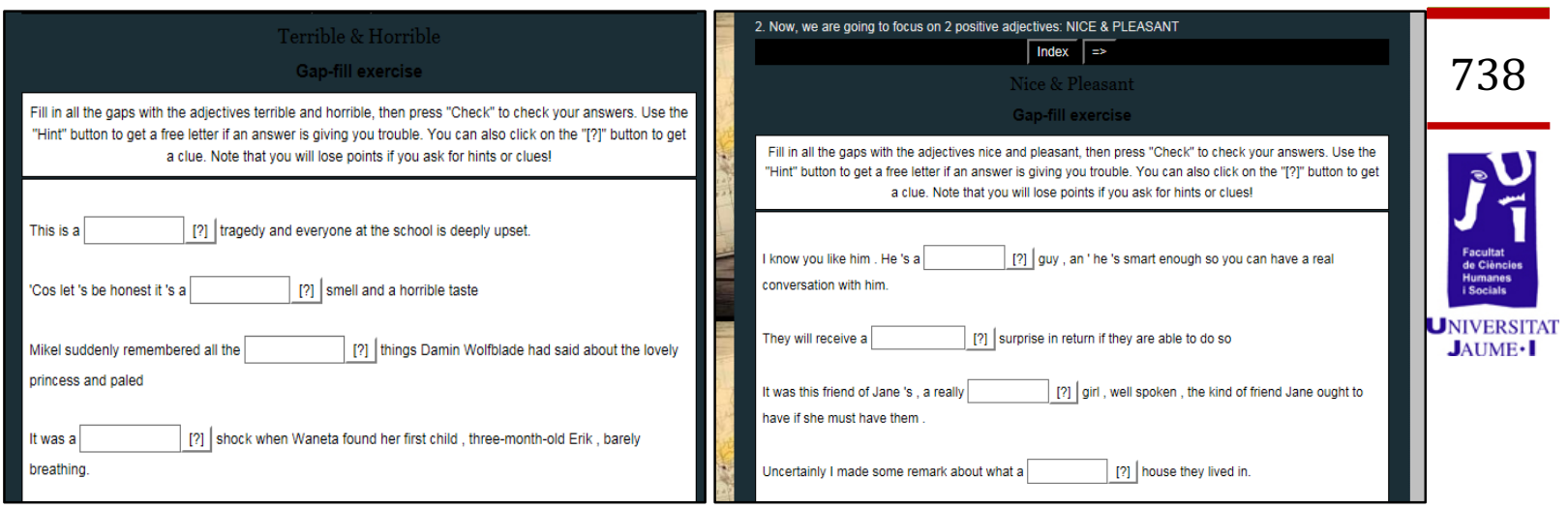

Figure 7. Examples of inductive activities

At the end of this stage, a review activity (see figure 8 ) is also presented to students to check if they master evaluative adjectives. If not, more activities for reinforcement can be offered.

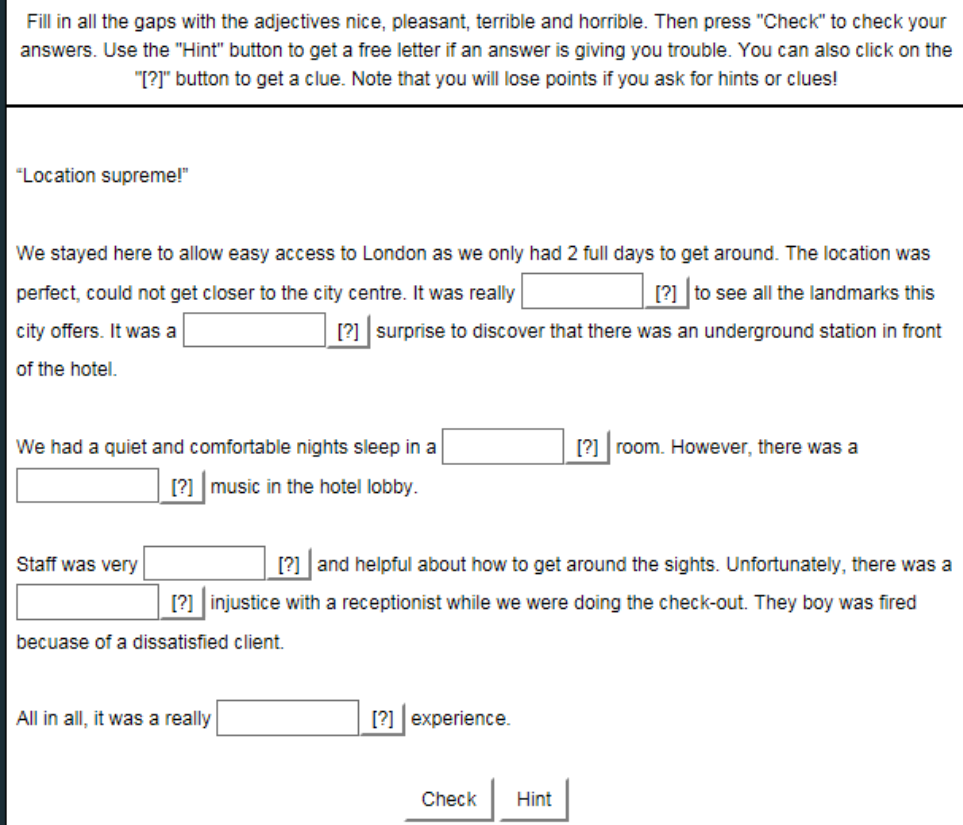

Figure 8. Review activity

\section{POST-TASK:}

Finally, the post-task or final task (see figure 9) consists on writing a hotel review applying all the aspects they have learned in the previous stages. 


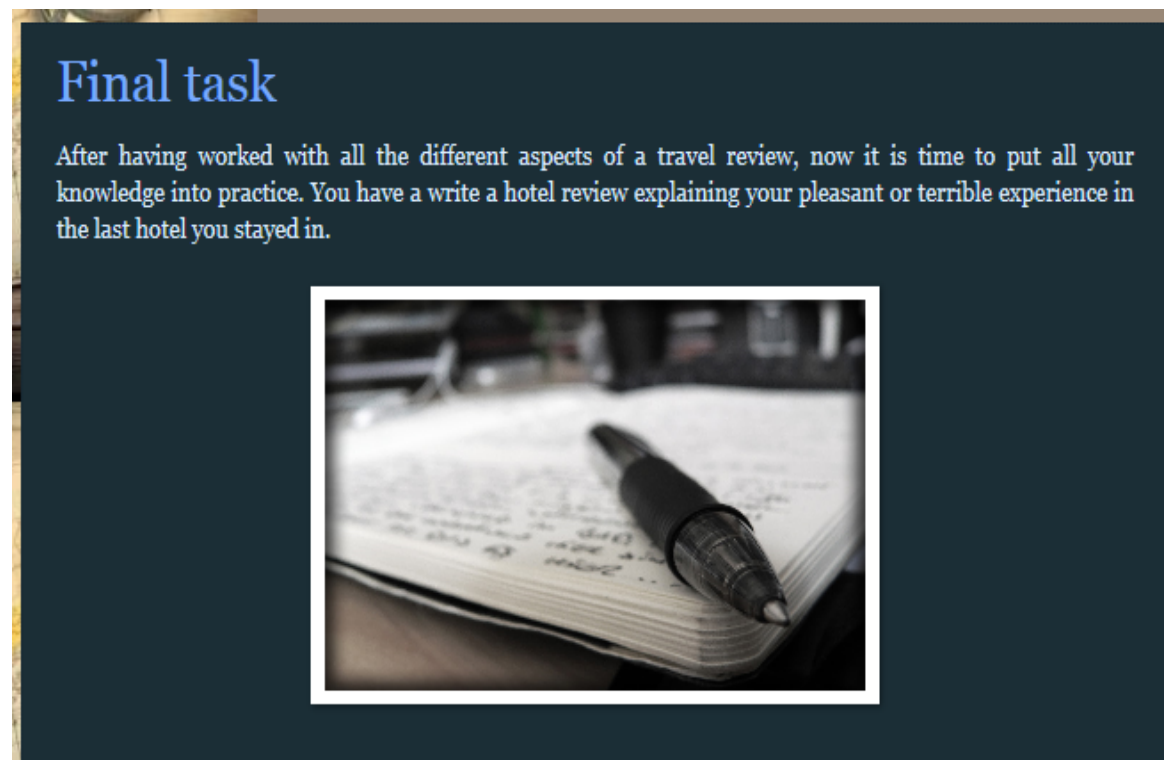

Figure 9. Final task

\section{Pros and cons of this teaching proposal:}

This teaching proposal helps teachers to create a space where being able to work with students inside or outside the classroom. What is more, it follows a TBLT methodology where students are going to obtain a final outcome (writing a hotel review) that is going to be really useful for their real life.

This activity will enhance students' motivation. Students should feel more excited because they will be working with new technologies and different tools such as blogs, forums, vokis, corpus or hot potatoes among others. Besides, they will have the chance of working using authentic material.

Realia and authentic material are used throughout the whole teaching proposal. Thus, creating a realistic environment where students are going to feel comfortable because they are going to feel a real need for using the English language.

Students will learn in a collaborative environment, through constructivism and experiential learning. Part of this activity is designed to work in teams, so, collaboration among students is essential. Besides, they will experiment in order to build their own knowledge.

As a limitation I should point out the time needed to design the blog and the different activities. I would also point out the necessity to master HTML language in order to attach different tools such as vokis or hot potatoes activities within the blog. 
As we have seen throughout this paper, blogs offer many possibilities for educators and provide many advantages in the language learning process. Blogs create sense of community among its users allowing learners to feel more secure and enhancing the language learning. They are also good tools for collaborative projects where students can work together fostering interaction among them. Furthermore, blogs also allow students to build their own knowledge. Finally, we cannot forget that blogs are going to enhance students' motivation due to the fact that they are working with new technologies in a friendly atmosphere.

In this paper, we have also seen the main advantages of CLT and TBLT. And finally, a pedagogical proposal has been devised with the aim of integrating tasks using a TBLT approach into a blog.

Apart from all the advantages mentioned, there are also limitations when working with blogs. The main limitation deals with time. A lot of time is needed to create and design both the blog and the activities or tasks that will be included. Besides, sometimes technical problems can arise.

Just to conclude I would like to say that even though designing this teaching proposal using ICT's has not been an easy task, the result has been really rewarding. I have learned a lot and I have had the opportunity to show my potential. What is more, I really feel this blog could be applied in a real classroom, so this is going to be my next step. And finally I would like to conclude by saying that students are going to be really motivated working with this blog as they are working with new technologies in a collaborative environment.

\section{References}

CHEN, C \& LAl, H. (2011): «Factors influencing secondary school teachers' adoption of teaching blogs». Computers \& Education 56, 948-960.

ELLIS, R. \& SHINTANI, N. (2014): "Task-based Language Teaching», in Ronald CARTER \& Guy Cook (eds), Exploring Language Pedagogy through Second Language Acquisition Research, Routledge, New York.

GARRISON, D. \& AKYOL, Z. (2009): «Role of instructional technology in the transformation of higher education». Journal of Computing in Higher Education, 21(1), 19-30.

Halic, O., Lee, D., Palaus, T. \& Spence, M. (2010): «To blog or not to blog: Student perceptions of blog effectiveness for learning in a college-level course». Internet and Higher Education, 13, 206-213.

MCMILLAN, D. W., \& CHAVIS, D. M. (1986): "Sense of community: A definition and theory". Journal of Community Psychology, 14(1), 6-23.

PrabHu, N.S. (1987): Second Language Pedagogy: A Perspective, Oxford University Press, Oxford. 
SARASON, S.B. (1974): The psychological sense of community: Prospects for a community psychology, Jossey-Bass, San Francisco.

Trajtemberg, C. \& YiakoumetTI, A. (2011): «Weblogs: a tool for EFL interaction, expression, and self-evaluation». ELT Journal, 65(4). DOI:10.1093/ELT/CCR015 WILLIS, J. (1996): A Framework for Task-based Learning, Longman, Harlow. 